\title{
A Potentially Useful Procedure for Conversion of Ethers to Esters
}

\author{
Hengguang $\mathrm{Li}^{1 *}$, Zaniya Mark ${ }^{1}$, Marion Graylion ${ }^{1}$ and Taipeng Shen ${ }^{2}$ \\ ${ }^{1}$ Department of Chemistry and Physics, Fayetteville State University, Fayetteville, North Carolina, USA \\ ${ }^{2}$ Sichiuan Cancer Hospital \& Institute, Sichuan Cancer Center, School of Medicine, University of Electronic Science and technology, Chengdu, China
}

*Corresponding author: Hengguang Li, Department of Chemistry and Physics, Fayetteville State University, Fayetteville, North Carolina, USA, E-mail: hli@uncfsu.edu

Received: 01 Jul, 2019 | Accepted: 15 Jul, 2019 | Published: 19 Jul, 2019

Citation: Li H, Mark Z, Graylion M, Shen T (2019) A Potentially Useful Procedure for Conversion of Ethers to Esters. J Med Chem Drug Des 2(2): dx.doi.org/10.16966/2578-9589.115

Copyright: (C) $2019 \mathrm{Li} \mathrm{H}$, et al. This is an open-access article distributed under the terms of the Creative Commons Attribution License, which permits unrestricted use, distribution, and reproduction in any medium, provided the original author and source are credited.

\section{Abstract}

This communication reports a catalytic system for transformation of ethers into their corresponding esters, especially for cyclic ethers. This efficient procedure was developed as part of our efforts to synthesize nucleoside building blocks and their derivatives. Gas Chromatography-Mass Spectrometry (GC-MS) monitored the reaction processes, Nuclear Magnetic Resonance Spectrometry (NMR), and Infrared Spectrometry (IR) were used to verify the structure of the products. The conversions of Tetrahydrofuran (THF) and other cyclic ether into lactones were accomplished in high yield, over $95 \%$. This approach could be extended too many types of ethers to produce directly corresponding esters simply. Four representatives of ethers were investigated. Cyclic ethers have the higher yields. Linear ethers gave lower yields. The reaction on methoxylcarbon or methyl ether carbon was not observed. The reacted catalyst can be reused over several times. For each reusing, only drops of sulfuric acid need to be added. Nevertheless, the asymmetric ethers selectivity needs to be addressed in future studies.

Keywords: Ether; Ester; Catalyst; Heterogonous

\section{Introduction}

Ethers are relatively unreactive compounds. The ether linkage is quite stable to bases, oxidizing and reducing agents. The ether linkage undergoes mostly one type of reaction and that is cleavage by strong acids. On the other hand, the common method to prepare esters is that carboxylic acids and the derivatives couple with alcohols under different mechanisms in the manner of esterification [1].

In this report, we chose cyclic ester, Gamma-Butylactone (GBL), as a model substitute, because it has widespread industrial use. It is a common solvent found in paint strippers, nail polish removers, stain removers, and circuit board cleaners. It is also a common intermediate in industrial chemistry including the manufacture of pyrrolidones and in some pharmaceuticals. International production and trade of GBL are at least of the order of hundreds of thousands of metric tons. Single consignments can be up to 500 tons alone [2].

Preparation of GBL is conventionally accomplished by intramolecular removal of water or distillation approaches conversion of Gamma-Hydroxybutyric Acid (GHB). It may also be obtained via oxidation of THF. Such process affords GBL in yields of up to $80 \%$, utilizes bromine generated in situ from an aqueous solution of sodium bromate and potassium hydrogen sulfate [3]. Despite efforts to curb GHB and GBL abuse, clandestine chemists are finding ways to obtain the desired substance. Since THF is a common solvent in most chemical laboratories and 1,4-butanediol (1,4-BD) is readily available, the above oxidation and dehydration reactions offer a high potential for either direct ingestion or subsequent conversion into GHB [4,5]. $\gamma$-Butyrolactone is commonly synthesized from sodium $\gamma$-hydroxybutyrate (GHB), or 1,4-butanediol (BDO) [6]. It is possible that endogenous GHB is involved in mammalian hibernation. It has been used in the treatment of alcoholism [7].

Homogenous sulfuric acidic catalyzes ethers to give alkyl hydrogen sulphate inevitably, however, we found heterogeneous charcoal and concentrated sulfuric acid mixture causes a different result. The carbon adjacent to the oxygen on the ether was oxidized into carbonyl without any other side reactions (Figure 1).

THF was converted to GBL in the presence of acidified charcoal, after refluxing for over 24 hours the product was higher yield and purity. A similar result occurred on the six-member ring ether, tetrahydro-pyran.<smiles>C1COCCO1</smiles>

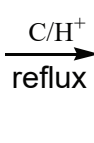<smiles>O=C1C[AlH]CO1</smiles>

$\mathrm{n}=1,2$

Figure 1: Cyclic symmetric ethers conversion 


\section{Experiment, Results, and Discussion}

Charcoal was treated with concentrated sulfuric acid first. To the 0.50 grams of charcoal in a flask was added two drops of concentrated sulfuric acid under $\mathrm{N}_{2}$ atmosphere, mixed with shacking or stirring. $10 \mathrm{~mL}$ ether was added, and the mixture was heated to reflux for over 24 hours. The reactions were monitored by GC-MS. Cyclic ethers resulted esters were determined by NMR and IR spectrometers additionally. The reacted catalyst had been reused over several times. For each reusing, only drops of sulfuric acid need to be added.

Instruments, GC-MS: GCMS-QP2010 SE, Shimadzu; NMR: Jeol $400 \mathrm{MHz}$; IR: IRPrestige-21, Shimadzu (Figure 2).

Because of the good results on the cyclic ethers, we expended the reactions on the other ethers, shown as figure 3.

\section{Linear symmetric ethers conversion}

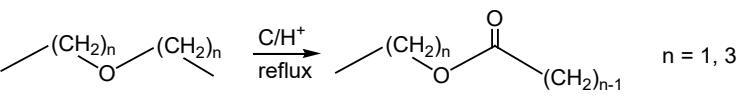

$$
\begin{aligned}
& \sim 10 \%-30 \%
\end{aligned}
$$

\section{Glycol ether conversion}<smiles>COCCOCCOCC#[13C]CCOCCOCCOC(=O)COCCOCCOC</smiles>

\section{Methyl ether conversion}

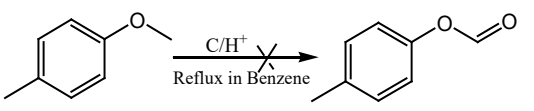

\section{Asymmetric ethers conversion (unknown)}

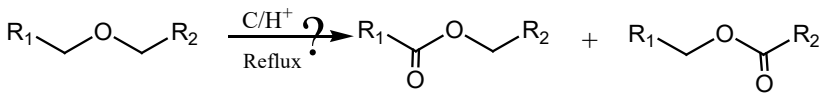

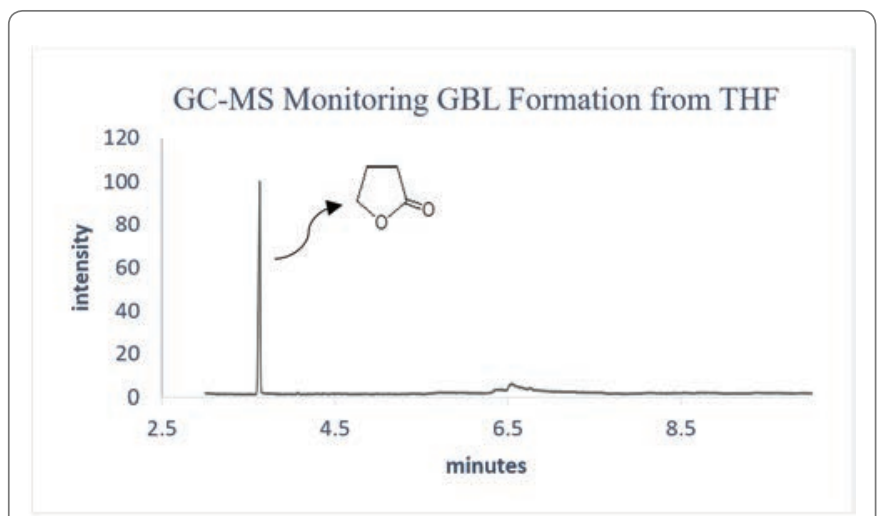

Figure 2: GC-MS of GBL from the reaction mixture after 24 hours.

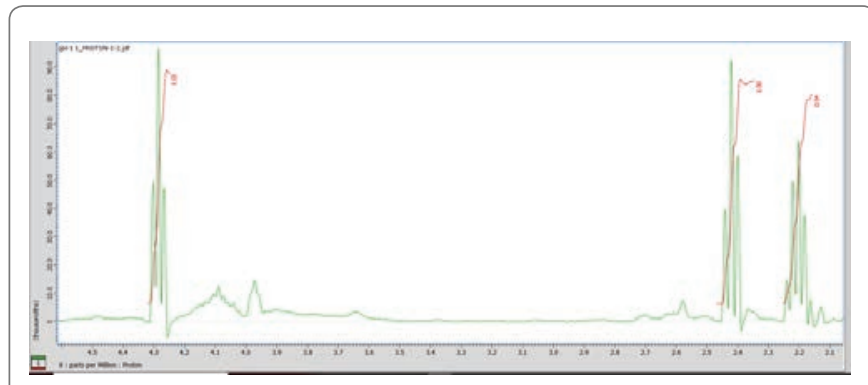

Figure 3: ${ }^{1} \mathrm{HNMR}$ of $\mathrm{GBH}$ without purification

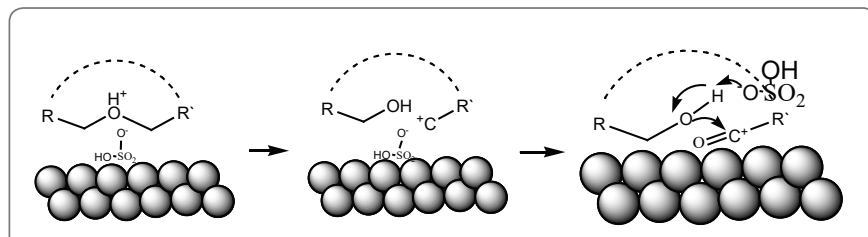

Figure 4: The hypothetic mechanism.

Owing to the conversions of Tetrahydrofuran (THF) and other cyclic ether into lactones given high yield, over 95\%, the approach could be expended to many types of esters produced from corresponding ethers. Four representatives of ethers were investigated. However, throughout this study we found that the esters formations were quite different in the alternatives, cyclic ethers were the most efficient, linear ethers have lower yields, the reaction on the methoxyl carbon or methyl ether has not been observed. However, the asymmetric ethers selectivity needs to be addressed in further studies. Thus, the reactivity was ranked as below. The conditions were optimized by changing the ratio, adjusting the temperature, and times.

Cyclic ether $>$ Linear ether $>$ Methoxyl or methyl ether

\section{The hypothetic mechanism}

The mechanism of this reaction is not clear yet, we hypothesize that the reaction occurs on the surface of the catalyst, on which ether oxygen is protonated first, carbocation formed on the oxygen adjacent substituted carbon second via breaking of $\mathrm{O}-\mathrm{C}$ bond. Then oxidation of carbocation followed with nucleophilic substitution to form the ester bond (Figure 4).

\section{Conclusion}

In conclusion, this report provides a feasible, simple, and economical, and environment-friendly approach to convert ether to the corresponding ester, particularly for the cyclic ethers in comparison with the earlier reported approaches. It may also provide a potential way to convert the polyglycol into the degradable polyester. The asymmetric ethers selectivity needs to be addressed in future studies. The reaction mechanism is not clear; we hypothesize as above, it worth being studied in the future.

\section{References}

1. Tingle J Bishop (1906) Reports: Esterification. In: Ira Remsen, Charles August Rouiller (eds) American Chemical Journal. University of lowa, USA 35: 368-369. 
2. World Health Organization (2014) WHO Expert Committee on Drug Dependence. Thirty-sixth Report, Geneva, Switzerland 16-20.

3. Metsger L, Bittner S (2000) Autocatalytic oxidation of ethers with Sodium Bromate. Tetrahedron 56: 1905-1910.

4. Morris JA (2000) Potential for gamma-Butyrolactone synthesis from tetrahydrofuran and 1,4-butanediol. Microgram XXXIII: 321-324.

5. Ogato $\mathrm{Y}$, Kohtaro T, Ikeda $\mathrm{T}$ (1980) Novel oxidation of tetrahydrofuran to gamma-butyrolactone with peroxyphosphoricacid. J Org Chem 45: 1320-1322.

6. Bozak RE, Knittel J, Hicks RJ (1998) Convenient Synthesis of a Lactone, $\gamma$-Butyrolactone. J Chem Educ 75: 84.

7. Nwaukwa SO, Keehn PM (1982) The oxidation of alcohols and ethers using Calcium Hypochlorite. Tet Lett 23: 35-38. 